\title{
VALIDATION OF THE PHYSICAL WORKING CAPACITY AT THE FATIGUE THRESHOLD TREADMILL TEST
}

\author{
Clayton L. Camic, Chelsea J. Hahn, Benjamin C. Hendrickson, and Andrew R. Jagim \\ Human Performance Laboratory, Exercise and Sport Science, \\ University of Wisconsin-La Crosse, La Crosse, USA
}

Original scientific paper UDC: $796.422: 519.2$

\begin{abstract}
:
The purposes of the present study were twofold: 1) to determine the physical working capacity at the fatigue threshold $\left(\mathrm{PWC}_{\mathrm{FT}}\right)$ during an incremental treadmill test, and 2) to examine the validity of this fatigue threshold through constant-velocity runs to exhaustion at 90,100 , and $110 \%$ of the estimated $\mathrm{PWC}_{\mathrm{FT}}$. Twelve aerobically-trained males (mean age $\pm \mathrm{SD}=24.6 \pm 5.4$ years, running volume $=69.9 \pm 46.0 \mathrm{~km} \cdot \mathrm{wk}^{-1}, \mathrm{n}=9$ ) and females $\left(22.3 \pm 2.3\right.$ years, $\left.45.6 \pm 4.6 \mathrm{~km} \cdot \mathrm{wk}^{-1}, \mathrm{n}=3\right)$ volunteered to perform a treadmill test to exhaustion with electromyographic $(E M G)$ signals recorded from the $\mathrm{m}$. vastus lateralis on four separate visits. The first visit required each subject to complete an incremental treadmill test to exhaustion for determination of their $\mathrm{PWC}_{\mathrm{FT}}$. During the second, third, and fourth visit, the subjects completed a treadmill run to exhaustion at a constant velocity that corresponded to 90,100 , or $110 \%$ of their $\mathrm{PWC}_{\mathrm{FT}}$ in random order. The linear regression analyses indicated there were no significant ( $\mathrm{p}>05$ ) changes in muscle activation (i.e. EMG amplitude) across time to exhaustion during the constant velocity runs at $90 \%(60.00 \pm 0.00 \mathrm{~min})$ and $100 \%(48.86 \pm 14.59 \mathrm{~min})$ $\mathrm{PWC}_{\mathrm{FT}}$, but significant $(\mathrm{p}<.05)$ increases occurred at $110 \% \mathrm{PWC}_{\mathrm{FT}}(19.44 \pm 10.26 \mathrm{~min})$. Thus, the findings of the present study indicated that the $\mathrm{PWC}_{\mathrm{FT}}$ treadmill test was able to accurately estimate the fastest running velocity that could be maintained for an extended period of time without evidence of neuromuscular fatigue.
\end{abstract}

Key words: muscle activation, EMG amplitude, running, $P W C_{F T}$

\section{Introduction}

Theoretically, the physical working capacity at the fatigue threshold $\left(\mathrm{PWC}_{\mathrm{FT}}\right)$ treadmill test estimates the fastest running velocity that can be maintained for an extended period of time without evidence of neuromuscular fatigue (Camic, Kovacs, Enquist, VanDusseldorp, \& Hill, 2014). Derived from the original $\mathrm{PWC}_{\mathrm{FT}}$ model of deVries et al. (1990) used for cycle ergometry, the $\mathrm{PWC}_{\mathrm{FT}}$ treadmill test is based on within-stage increases in electromyographic (EMG) amplitude that reflect fatigueinduced increases in muscle activation required to maintain the desired running velocity. Specifically, this protocol involves recording six 10 -second EMG epochs (10-20, 30-40, 50-60, 70-80, 90-100, and $110-120$ seconds) during each two-minute stage of a treadmill test to exhaustion that incrementally increases in velocity with the grade remaining constant (1\%). The EMG amplitude values associated with these 10 -second epochs are then plotted across time for each stage (i.e. running velocity) and the slope coefficient of this relationship is tested for significance. The $\mathrm{PWC}_{\mathrm{FT}}$ is then defined as the average of the highest running velocity that results in a non-significant ( $p>.05)$ slope coefficient and the lowest running velocity that results in a significant $(\mathrm{p}<.05)$ positive slope coefficient.

The onset of neuromuscular fatigue determined by the $\mathrm{PWC}_{\mathrm{FT}}$ treadmill test has been demonstrated to occur at the same running velocity $(14.0 \pm 2.3$ $\left.\mathrm{km} \cdot \mathrm{hr}^{-1}\right)$ and to be significantly correlated $(\mathrm{r}=0.70)$ with the respiratory compensation point $(14.0 \pm 1.8$ $\left.\mathrm{km} \cdot \mathrm{hr}^{-1}\right)$ in aerobically-trained subjects $(\mathrm{n}=15)$ (Camic, et al., 2014). These findings (Camic, et al., 2014) suggested that the $\mathrm{PWC}_{\mathrm{FT}}$ treadmill test, like the respiratory compensation point, can be used to identify the boundary between the heavy and severe domains of exercise intensity which represents the maximal exercise intensity that can be maintained with oxygen uptake and lactate still reaching a steady state (Gaesser \& Poole, 1996). For example, the respiratory compensation point defined by Beaver, Wasserman, and Whipp (1986) as the breakpoint in the minute ventilation versus carbon dioxide production relationship marks the beginning phase of relative hyperventilation due to metabolic acidosis. Regardless of training status, it has been shown (Poole, Ward, Gardner, \& Whipp, 
1988; Poole, Ward, \& Whipp, 1990) that constant intensity exercise above this threshold (i.e. within the severe domain) is only sustainable for up to 20 minutes (mean $\pm \mathrm{SD}$ time: pre-training $=17.7 \pm 1.2$ min; post-training $=17.1 \pm 1.3 \mathrm{~min})$. Ribeiro et al. (1986), however, illustrated that constant intensity exercise at this threshold (i.e. the border between heavy and severe) can be maintained for at least 40 minutes. Although these findings (Beaver, et al., 1986; Camic, et al., 2014; Gaesser \& Poole, 1996; Poole, et al., 1988, 1990; Ribeiro, et al., 1986) provide a physiological basis for the $\mathrm{PWC}_{\mathrm{FT}}$ model as a fatigue threshold to identify sustainable exercise intensities during treadmill running, this test has yet to be validated through constant-velocity runs to exhaustion below, at, and above the estimated $\mathrm{PWC}_{\mathrm{FT}}$. If valid, potential uses for the $\mathrm{PWC}_{\mathrm{FT}}$ treadmill test include both the athletic performance and rehabilitative applications as during cycle ergometry (Camic, et al., 2010b; deVries, et al., 1989; Emerson, et al., 2014; Jenkins, et al., 2014; Stout, et al., 2007a, 2007b, 2015; Zak, et al., 2015 ) that includes assessing physical fitness, evaluating the effectiveness of conditioning programs and nutritional supplements, prescribing exercise training intensities, and examining factors related to neuromuscular function in the elderly. Based on these practical applications and popularity of running, an examination into the validity of the $\mathrm{PWC}_{\mathrm{FT}}$ treadmill test is warranted. Therefore, using the validation method of Briscoe, Forgach, Trifan, and Malek (2014) for the $\mathrm{PWC}_{\mathrm{FT}}$ during cycle ergometry, the purposes of the present study were twofold: 1) to determine the $\mathrm{PWC}_{\mathrm{FT}}$ during an incremental treadmill test, and 2) to examine the validity of this fatigue threshold through constantvelocity runs to exhaustion at 90,100 , and $110 \%$ of the estimated $\mathrm{PWC}_{\mathrm{FT}}$. We hypothesized that: 1) the constant velocity runs to exhaustion at 90 and $100 \%$ $\mathrm{PWC}_{\mathrm{FT}}$ would result in no significant changes in muscle activation across time to exhaustion (TTE) (i.e., a non-significant slope coefficient for the EMG amplitude versus TTE relationship), whereas there would be significant fatigue-induced increases in muscle activation at $110 \% \mathrm{PWC}_{\mathrm{FT}}$ (i.e., a positive slope coefficient for the EMG amplitude versus TTE relationship); and 2) the TTE values for 90, 100, $110 \% \mathrm{PWC}_{\mathrm{FT}}$ would be approximately $\geq 60,40-60$, and $\leq 30$ minutes, respectively.

\section{Methods}

\section{Subjects}

Twelve aerobically-trained males (mean age $\pm \mathrm{SD}=24.6 \pm 5.4$ years, body mass $=77.5 \pm 10.0$ $\mathrm{kg}$, body height $=181.7 \pm 8.3 \mathrm{~cm}$, running volume $=69.9 \pm 46.0 \mathrm{~km} \cdot \mathrm{wk}^{-1}, \mathrm{n}=9$ ) and females $(22.3 \pm 2.3$ years, $59.9 \pm 11.9 \mathrm{~kg}, 170.3 \pm 11.8 \mathrm{~cm}$, $45.6 \pm 4.6 \mathrm{~km} \cdot \mathrm{wk}^{-1}, \mathrm{n}=3$ ) volunteered to participate in this investigation. These subjects were selected based on their diverse running backgrounds that included regular participation in recreational races (i.e. $5 \mathrm{~K}, 10 \mathrm{~K})(\mathrm{n}=3)$, marathons $(\mathrm{n}=5)$, ultramarathons $(\mathrm{n}=2)$, and triathlons $(\mathrm{n}=2)$. Each subject visited the laboratory on four occasions (separated by at least 48 hours), had prior familiarization with treadmill running, and was instructed to: 1) maintain normal dietary habits and sleep patterns during the course of the study, and 2) avoid exercise for 48 hours, caffeine and alcohol for 24 hours, and food intake for three hours prior to each visit. The study was approved by the University Institutional Review Board for Human Subjects and all subjects completed a health history questionnaire and signed a written informed consent prior to testing.

\section{Incremental Treadmill Test (Visit 1)}

During the first laboratory visit, each subject performed an incremental treadmill (Fitnex Fitness Equipment, Inc., Dallas, TX) test to exhaustion for determination of their $\mathrm{PWC}_{\mathrm{FT}}$. This test involved a warm-up of walking at $6.4 \mathrm{~km} \cdot \mathrm{h}^{-1}$ for five minutes. Subjects were also provided five minutes to perform 3-4 short strides at a self-selected intensity. Immediately following the warm-up, the test began at 9.0 $\mathrm{km} \cdot \mathrm{hr}^{-1}$ and increased $1.0 \mathrm{~km} \cdot \mathrm{hr}^{-1}$ every two minutes until volitional cessation. This stage increment of $1.0 \mathrm{~km} \cdot \mathrm{hr}^{-1}$ was modified from $1.6 \mathrm{~km} \cdot \mathrm{hr}^{-1}$ of the original protocol (Camic, et al., 2014) to increase the precision of estimating $\mathrm{PWC}_{\mathrm{FT}}$ in the current sample. The grade remained constant at $1.0 \%$ during the test and was selected to represent the energy cost that is typically experienced by running outdoors (Jones \& Doust, 1996). The subjects were strongly encouraged during the test to achieve the longest exercise time possible. Each subject was also fitted with a Polar Heart Watch system (Polar Electro Inc., Lake Success, NY) to monitor heart rate throughout the test. The maximal test was deemed valid if all three of the following criteria were attained: 1) $90 \%$ of age-predicted maximal heart rate, 2) rating of perceived exertion (RPE) $\geq 18$, and 3) volitional cessation due to fatigue. The highest heart rate value achieved during this test was defined as peak heart rate $\left(\mathrm{HR}_{\text {peak }}\right)$ for the study.

\section{Determination of $\mathrm{PWC}_{\mathrm{FT}}$}

The $\mathrm{PWC}_{\mathrm{FT}}$ values were determined using the model of deVries et al. (1990). Specifically, during each two-minute stage of the incremental treadmill test, six 10-second EMG samples were selected from the signal $(10-20,30-40,50-60$, 70-80, 90-100, 110-120 seconds). The EMG amplitude (microvolts root mean square, $\mu \mathrm{Vrms}$ ) values were calculated for each of the 10-second epochs (MATLAB, Mathworks) and plotted across time for each stage (i.e. running velocity) of the test. The 
$\mathrm{PWC}_{\mathrm{FT}}$ was then determined by averaging the highest running velocity that resulted in a nonsignificant ( $\mathrm{p}>.05$, single-tailed $t$-test) slope coefficient for the EMG amplitude versus time relationship, with the lowest running velocity that resulted in a significant $(\mathrm{p}<.05)$ positive slope coefficient (Table 1).

\section{Runs to exhaustion at 90,100 , and $110 \%$ PWC $_{\mathrm{FT}}$ (Visits 2-4)}

During the second, third, and fourth laboratory visits, each subject ran on the treadmill to volitional fatigue at a constant velocity that corresponded to 90,100 , or $110 \%$ of their $\mathrm{PWC}_{\mathrm{FT}}$ in random order. The constant velocity runs began with a warm-up that involved walking at $6.4 \mathrm{~km} \cdot \mathrm{hr}^{-1}$ and $1.0 \%$ grade for five minutes, followed by a 5-minute jog that corresponded to $50 \%$ of their $\mathrm{PWC}_{\mathrm{FT}}$. Subjects were also provided five minutes to perform 3-4 short strides at a self-selected intensity. After the warm-up, the subjects ran on the treadmill at the constant velocity that corresponded to 90,100 , or $110 \%$ of their $\mathrm{PWC}_{\mathrm{FT}}$ with the grade remaining at $1.0 \%$. The subjects were encouraged to maintain this running velocity for as long as possible or until they could no longer safely maintain their stride. The time duration of 40-60 minutes was defined a priori as an extended period of time based on the time limits of constant intensity exercise at the upper limit of the heavy exercise intensity domain (Gaesser \& Poole, 1996; Ribiero, et al., 1986). If the 60-minute time point was reached prior to volitional fatigue, the test was terminated at this point. Verbal encouragement was provided to the subjects throughout each test. During the runs to exhaustion, 60-second EMG samples were selected from the signal $(0-60,60-120,120-180, \ldots$ seconds) for the duration of the test. The EMG amplitude values were calculated for each of these 60 -second epochs and separately plotted across the total time duration of each test.

\section{EMG measurements and signal processing}

During all laboratory visits, a bipolar $(10 \mathrm{~mm}$ center-to-center) wireless surface electrode sensor (Tringo Wireless EMG, Delsys Inc., Natick, MA) was placed on the right thigh over the vastus lateralis muscle according to the recommendations of the SENIAM Project (Hermens, et al., 1999) and secured with multipurpose prewrap tape (Mwrap ${ }^{\circledR}$, Mueller Sports Medicine, Inc., Prairie du Sac, WI). Prior to electrode placement, the skin at the elec- trode site was shaved, carefully abraded with gauze, and cleaned with alcohol. The EMG signals were amplified (gain: x1000) (Tringo Wireless EMG, Delsys Inc., Natick, MA, bandwidth=20-450 Hz), sampled at $2000 \mathrm{~Hz}$, recorded continuously throughout each test, and stored in a personal computer (Latitude E6540, Dell, Inc., Round Rock, TX) for subsequent analyses. All signal processing was performed using custom programs, which were written with MATLAB programming software (version 8.2, Mathworks, Natick, MA). The EMG signals were digitally bandpass filtered (fourthorder Butterworth) at 20-450 Hz.

\section{Statistical analyses}

The EMG amplitude values for each subject were normalized to the highest value attained during each of the constant velocity runs. In addition, the TTE for each subject during each constant velocity run was normalized to the total time duration of the test. The relationships for normalized EMG amplitude versus normalized TTE for each subject and velocity were examined using linear regression (SPSS software program, Chicago, IL). Four separate one-way repeated-measures ANOVAs were used to determine whether there were significant mean differences in running velocity, TTE, final-minute RPE, and final-minute $\% \mathrm{HR}_{\text {peak }}$ at 90 , 100 , and $110 \% \mathrm{PWC}_{\mathrm{FT}}$. When appropriate, followup analyses included paired $t$-tests with Bonferroni correction $(0.05 / 3=0.0167)$. An alpha of $\mathrm{p}<.05$ was considered statistically significant for the linear regression and ANOVA analyses.

\section{Results}

Mean $\pm S D$ values were calculated for the $\mathrm{PWC}_{\mathrm{FT}}$, $\mathrm{RPE}$, and $\mathrm{HR}_{\text {peak }}$ values attained during the incremental test to exhaustion as well as the running velocity, TTE, final-minute RPE, and final-minute $\% \mathrm{HR}_{\text {peak }}$ values achieved during the constant velocities runs to exhaustion at 90,100 , and $110 \% \mathrm{PWC}_{\mathrm{FT}}$ 
(Table 2). The results indicated there were significant mean differences among the running velocities associated with 90,100 , and $110 \% \mathrm{PWC}_{\mathrm{FT}}$ (Table 2). In addition, TTE was significantly shorter during the $110 \% \mathrm{PWC}_{\mathrm{FT}}$ run to exhaustion compared to 90 and $100 \%$ (Table 2). Individually, ten of the 12 subjects $(83.3 \%)$ were able to maintain the running velocity associated with $100 \% \mathrm{PWC}_{\mathrm{FT}}$ for at least 40 minutes, whereas only one of the subjects $(8.33 \%)$ was able to maintain $110 \% \mathrm{PWC}_{\mathrm{FT}}$ for more than 30 minutes. All subjects maintained $90 \% \mathrm{PWC}_{\mathrm{FT}}$ for 60 minutes. Final-minute $\mathrm{RPE}$ and $\% \mathrm{HR}_{\text {peak }}$ values were significantly lower during the $90 \% \mathrm{PWC}_{\mathrm{FT}}$ run to exhaustion compared to 100 and $110 \%$ (Table 2). For the nine individuals that were able to maintain $100 \% \mathrm{PWC}_{\mathrm{FT}}$ for $\geq 40$ minutes or $110 \% \mathrm{PWC}_{\mathrm{FT}}$
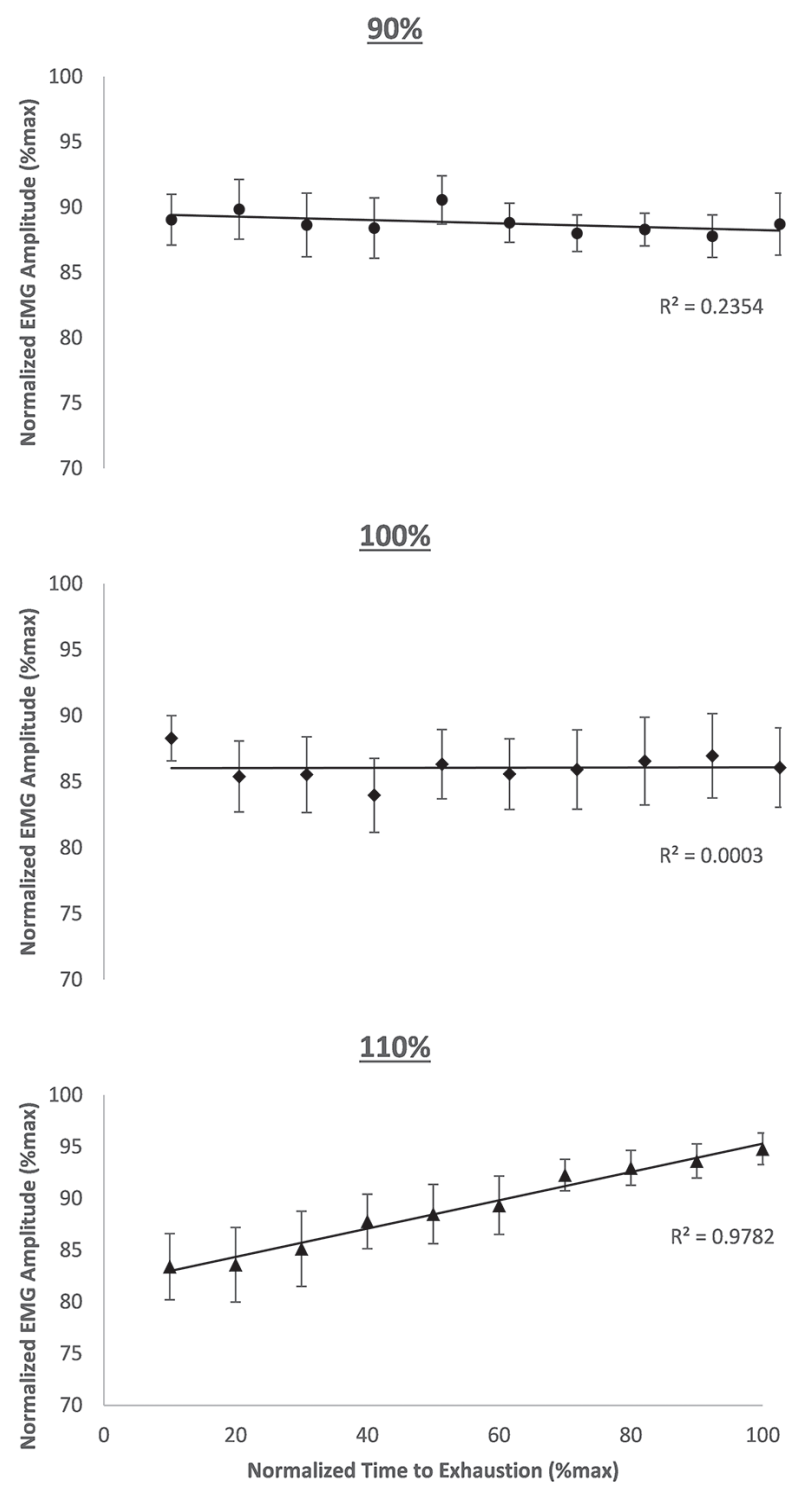

Figure 1. The composite data (mean $\pm S E$ ) for the normalized EMG amplitude across normalized time to exhaustion at 90,100 , and $110 \%$ of the $P W C_{F T}$. The slope coefficients for the normalized EMG amplitude versus normalized time to exhaustion relationships were not significantly $(p>05)$ greater than zero at 90 and $100 \% P W C_{F T}$, but were significantly $(p<.05)$ greater than zero at $110 \% P W C_{F T}$. for $\leq 30$ minutes, the normalized EMG amplitude versus normalized TTE relationships resulted in non-significant slope coefficients during the runs to exhaustion at 90 and $100 \% \mathrm{PWC}_{\mathrm{FT}}$, but a significant slope coefficient at $110 \% \mathrm{PWC}_{\mathrm{FT}}$ (Figure 1).

\section{Discussion and conclusions}

The main finding of the present study indicated that the $\mathrm{PWC}_{\mathrm{FT}}$ treadmill test was a valid model for estimating the fastest running velocity that could be maintained without evidence of neuromuscular fatigue in the majority (75\%) of our subjects. Specifically, 10 of the 12 subjects $(83 \%)$ were able to maintain the running velocity associated with $100 \% \mathrm{PWC}_{\mathrm{FT}}$ for at least 40 minutes, whereas 11 of the 12 subjects $(92 \%)$ were not able to maintain $110 \% \mathrm{PWC}_{\mathrm{FT}}$ for more than 30 minutes (Table 2). All 12 subjects were able to maintain $90 \% \mathrm{PWC}_{\mathrm{FT}}$ for 60 minutes (Table 2). In addition, the composite data (i.e. slope coefficients) for the normalized EMG amplitude versus normalized TTE relationships were non-significant at 90 and $100 \% \mathrm{PWC}_{\mathrm{FT}}$, but significant at $110 \% \mathrm{PWC}_{\mathrm{FT}}$ (Figure 1). These findings suggested that the constant velocity runs to exhaustion at 90 and $100 \% \mathrm{PWC}_{\mathrm{FT}}$ resulted in a no significant change in muscle activation across time,

Table 2. Running velocities, heart rate, rating of perceived exertion, and time to exhaustion values during the $P W C_{F T}$ treadmill test (Visit 1) and constant velocity runs to exhaustion (Visits 2-4)

\begin{tabular}{|c|c|}
\hline Variables & Mean $\pm S D$ \\
\hline \multicolumn{2}{|l|}{ Visit 1} \\
\hline Maximal running velocity $\left(\mathrm{km} \cdot \mathrm{hr} \mathrm{r}^{-1}\right)$ & $16.0 \pm 1.8$ \\
\hline Peak heart rate (beats $\cdot \mathrm{min}^{-1}$ ) & $186.4 \pm 9.5$ \\
\hline Maximal RPE (6-20) & $19.3 \pm 1.0$ \\
\hline \multicolumn{2}{|l|}{ Visits 2-4 } \\
\hline \multicolumn{2}{|l|}{$90 \% \mathrm{PWC}_{\mathrm{FT}}$} \\
\hline Running velocity $\left(\mathrm{km} \cdot \mathrm{hr} r^{-1}\right)$ & $11.6 \pm 1.5$ \\
\hline Time to exhaustion (min) & $60.00 \pm 0.00$ \\
\hline Final heart rate $\left(\% \mathrm{HR}_{\text {peak }}\right)$ & $91.2 \pm 3.8 \dagger$ \\
\hline Final RPE (6-20) & $14.3 \pm 2.6 \dagger$ \\
\hline \multicolumn{2}{|l|}{$100 \% \mathrm{PWC}_{\mathrm{FT}}$} \\
\hline Running velocity $\left(\mathrm{km} \cdot \mathrm{hr}{ }^{-1}\right)$ & $13.0 \pm 1.6$ \\
\hline Time to exhaustion (min) & $48.86 \pm 14.59$ \\
\hline Final heart rate $\left(\% \mathrm{HR}_{\text {peak }}\right)$ & $95.6 \pm 4.6$ \\
\hline Final RPE (6-20) & $17.8 \pm 2.3$ \\
\hline \multicolumn{2}{|l|}{$110 \% \mathrm{PWC}_{\mathrm{FT}}$} \\
\hline Running velocity $\left(\mathrm{km} \cdot \mathrm{hr}{ }^{-1}\right)$ & $14.3 \pm 1.8$ \\
\hline Time to exhaustion (min) & $19.44 \pm 10.26^{*}$ \\
\hline Final heart rate $\left(\% \mathrm{HR}_{\text {peak }}\right)$ & $98.7 \pm 3.8$ \\
\hline Final RPE $(6-20)$ & $19.1 \pm 1.1$ \\
\hline
\end{tabular}

*Significantly $(p<.05)$ different from $90 \%$ and $100 \% \mathrm{PWC}_{\mathrm{FT}}$ †Significantly $(p<.05)$ different from $100 \%$ and $110 \%$ PWC $_{\mathrm{FT}}$ 
whereas there were significant fatigue-induced increases in muscle activation at $110 \%$. Therefore, the $\mathrm{PWC}_{\mathrm{FT}}$ treadmill test was able to accurately identify the fastest non-fatiguing running velocity (i.e. $100 \% \mathrm{PWC}_{\mathrm{FT}}$ ) that could be maintained for an extended period of time in nine (75\%) subjects, but overestimated this threshold in two (17\%) subjects and underestimated in one subject $(8 \%)$.

For the two subjects that were not able to maintain $100 \% \mathrm{PWC}_{\mathrm{FT}}$ for at least 40 minutes (18.63 and 25.08 minutes), their final-minute $\% \mathrm{HR}_{\text {peak }}$ values were $95 \%$ at the 60 -minute time point during their constant velocity runs at $90 \% \mathrm{PWC}_{\mathrm{FT}}$. In addition, one subject that was able to maintain $110 \% \mathrm{PWC}_{\mathrm{FT}}$ for more than 30 minutes $(44.50 \mathrm{~min})$ exhibited a final-minute $\% \mathrm{HR}_{\text {peak }}$ of $97 \%$ during their constant velocity run at this intensity. Thus, the $\mathrm{PWC}_{\mathrm{FT}}$ treadmill test over- or underestimated the fastest running velocity that could be maintained by approximately $10 \%$ in these three subjects. The reason for this $10 \%$ error remains unclear, but may be attributable to differences in training regimens. Specifically, two of the three subjects were triathletes whose aerobic capacities and neuromuscular strategies have been developed using additional forms of training other than running alone (i.e. cycling and swimming). It is possible that these factors partially contributed to the $10 \%$ error found in these subjects and that the $\mathrm{PWC}_{\mathrm{FT}}$ treadmill test may exhibit approximately $\pm 10 \%$ error for estimating the running velocity associated with neuromuscular fatigue in triathletes. Future studies should further examine the validity of the $\mathrm{PWC}_{\mathrm{FT}}$ model for predicting fatiguing versus non-fatiguing running velocities in aerobically-trained individuals that include multiple forms of exercise into their training regimen.

Based on the findings of previous investigations (Camic, et al., 2014; Poole, et al., 1988, 1990; Ribeiro, et al., 1986), we hypothesized that the running velocities associated with 90,100 , and $110 \% \mathrm{PWC}_{\mathrm{FT}}$ could be maintained for approximately $\geq 60,40-60$, and $\leq 30$ minutes, respectively. In the present study, the running velocity at $100 \%$ $\mathrm{PWC}_{\mathrm{FT}}$ was sustained for $48.86 \pm 14.59$ minutes with the final-minute $\% \mathrm{HR}_{\text {peak }}$ and RPE values of $95.6 \pm 4.6 \%$ and $17.8 \pm 2.3$, respectively (Table 2). Ribeiro et al. (1986) has shown that constant intensity exercise at the border between the heavy and severe domains is maintainable for at least 40 minutes and results in $\% \mathrm{HR}_{\text {peak }}$ values that exceed $90 \%$. Thus, these TTE, RPE, and $\% \mathrm{HR}_{\text {peak }}$ values suggested that the subjects in the present study were at the upper limit of the heavy domain of exercise intensity during the $100 \% \mathrm{PWC}_{\mathrm{FT}}$ constant velocity run to exhaustion and were at or near their maximal level of exertion at completion. These findings were also consistent with those of Camic et al. (2014) that indicated the $\mathrm{PWC}_{\mathrm{FT}}$ during treadmill running occurs at the respiratory compensation point that demarcates the boundary between the heavy and severe domains of exercise intensity.

Previous investigations (Poole, et al., 1988, 1990; Ribeiro, et al., 1986) have shown that continuous exercise within the severe domain results in both oxygen uptake and blood lactate values failing to stabilize and subsequently reaching maximal levels, thereby leading to volitional fatigue within 20 minutes. For example, Poole et al. $(1988,1990)$ illustrated that constant intensity exercise within the severe domain results in TTE values of approximately 17-18 minutes, independent of training status. In the present investigation, the TTE $(19.44 \pm 10.26$ $\mathrm{min})$, final-minute RPE (19.1 \pm 1.1$)$, and final-minute $\% \mathrm{HR}_{\text {peak }}(98.7 \pm 3.8 \%)$ values during the constant velocity run to exhaustion at $110 \% \mathrm{PWC}_{\mathrm{FT}}$ suggested this intensity was within the severe domain (Table 2). Furthermore, the increase in running velocity from 100 to $110 \% \mathrm{PWC}_{\mathrm{FT}}$ resulted in an average decrease in TTE by $-29.42 \pm 10.20$ minutes and indicated that the intensity associated with $110 \%$ $\mathrm{PWC}_{\mathrm{FT}}$ surpassed the threshold for a sustainable level of muscle activation. The constant velocity run to exhaustion at $90 \% \mathrm{PWC}_{\mathrm{FT}}$, however, resulted in the TTE, final-minute RPE, and final-minute $\% \mathrm{HR}_{\text {peak }}$ values of $60.00 \pm 0.00$ minutes, $14.3 \pm 2.6$, and $91.2 \pm 3.8 \%$, respectively. These values during the $90 \% \mathrm{PWC}_{\mathrm{FT}}$ constant velocity run to exhaustion at the 60-minute time point suggested that this intensity was within (or below) the heavy domain, resulted in a constant level of muscle activation, and could have been maintained for significantly longer, depending on training level.

Recently, Briscoe et al. (2014) examined the validity of the $\mathrm{PWC}_{\mathrm{FT}}$ test as a neuromuscular fatigue threshold for identifying the highest sustainable non-fatiguing power output during cycle ergometry. This validation method (Briscoe, et al., 2014) involved determination of the $\mathrm{PWC}_{\mathrm{FT}}$ followed by constant workload rides to exhaustion at 70,100 , and $130 \%$ of the estimated $\mathrm{PWC}_{\mathrm{FT}}$. The authors (Briscoe, et al., 2014) illustrated that the workouts to exhaustion at 70 and $100 \%$ of the $\mathrm{PWC}_{\mathrm{FT}}$ resulted in no significant $(\mathrm{p}>.05)$ increases in EMG amplitude (i.e. muscle activation) across TTE (mean $\pm \mathrm{SD}=60.0 \pm 0.0 \mathrm{~min}$ and $47.2 \pm 4.1 \mathrm{~min}$, respectively), whereas a significant $(\mathrm{p}<.05) \mathrm{EMG}$ amplitude versus TTE relationship was observed at $130 \%$ of the $\mathrm{PWC}_{\mathrm{FT}}(11.3 \pm 2.7 \mathrm{~min})$ for all 11 subjects. Thus, the TTE values at $100 \% \mathrm{PWC}_{\mathrm{FT}}$ (48.9 vs. $47.2 \mathrm{~min}$ ) as well as below (60.0 vs. 60.0 min) and above $(19.4$ vs. $11.3 \mathrm{~min})$ the $\mathrm{PWC}_{\mathrm{FT}}$ were comparable between treadmill running and cycle ergometry. The validity differences for the $\mathrm{PWC}_{\mathrm{FT}}$ as the highest sustainable exercise intensity between treadmill running $(75 \%)$ and cycle ergometry $(100 \%)$, however, may be due to variations in methodology, mode of exercise, and training status. For example, the present study utilized the vali- 
dation method of Briscoe et al. (2014), but modified the exercise intensities below and above the estimated $\mathrm{PWC}_{\mathrm{FT}}$ from 70 and $130 \%$ to 90 and $110 \%$. This adjustment was completed to increase the precision in validation because it is unlikely that using running velocities associated with 70 and $130 \%$ of the $\mathrm{PWC}_{\mathrm{FT}}$ would provide a suitable range for comparison. In fact, running velocities associated with 70 and $130 \%$ of the estimated $\mathrm{PWC}_{\mathrm{FT}}\left(100 \%=13.0 \pm 1.6 \mathrm{~km} \cdot \mathrm{hr}^{-1}\right)$ would have yielded values of $9.1 \pm 1.1$ and $16.8 \pm 2.1 \mathrm{~km} \cdot \mathrm{hr}^{-1}$, respectively, compared to the intensities used in the present study $\left(90 \%=11.6 \pm 1.5 \mathrm{~km} \cdot \mathrm{hr}^{-1}\right.$ and $\left.110 \%=14.3 \pm 1.8 \mathrm{~km} \cdot \mathrm{hr}^{-1}\right)$. This modification allowed for running velocities of approximately $\pm 1.35 \mathrm{~km} \cdot \mathrm{hr}^{-1}( \pm 10 \%)$ from $100 \%$ $\mathrm{PWC}_{\mathrm{FT}}$ versus $\pm 3.85 \mathrm{~km} \cdot \mathrm{hr}^{-1}( \pm 30 \%)$ using 70 and $130 \%$. In addition, it has been demonstrated that the $\mathrm{PWC}_{\mathrm{FT}}$ during cycle ergometry identifies the boundary between the moderate and heavy domains of exercise intensity (Camic, et al., 2010a), whereas the $\mathrm{PWC}_{\mathrm{FT}}$ during treadmill running demarcates the heavy from severe domains (Camic, et al., 2014). This difference in exercise intensities associated with the $\mathrm{PWC}_{\mathrm{FT}}$ may be explained by the aerobically-trained runners participating in the present study and those used by Camic et al. (2014) for the treadmill test versus previous studies (Briscoe, et al., 2014; Camic, et al., 2010a) that recruited recreationally-active subjects for the cycle ergometry test, who may not have been accustomed to performing that type of exercise. Collectively, however, the findings of the present study and those of Briscoe et al. (2014) demonstrated that the $\mathrm{PWC}_{\mathrm{FT}}$ serves as a valid tool for estimating the maximal running velocity and power output than can be sustained for an extended period of time without fatigue- induced increases in muscle activation as indicated by changes in EMG amplitude.

In summary, the $\mathrm{PWC}_{\mathrm{FT}}$ treadmill test was able to identify the highest non-fatiguing running velocity by statistically examining the slope coefficients of the EMG amplitude (i.e. muscle activation) versus time relationships in the majority (75\%) of our subjects. Specifically, the constant velocity runs to exhaustion at 90,100 , and $110 \% \mathrm{PWC}_{\mathrm{FT}}$ resulted in the TTE, final-minute RPE, and final-minute $\% \mathrm{HR}_{\text {peak }}$ values (Table 2) consistent with exercise intensities within the heavy domain $\left(90 \% \mathrm{PWC}_{\mathrm{FT}}\right)$, at the border between the heavy and severe domain $\left(100 \% \mathrm{PWC}_{\mathrm{FT}}\right)$, and within the severe domain $(110 \%$ $\mathrm{PWC}_{\mathrm{FT}}$ ), respectively. In addition, the normalized EMG amplitude versus normalized TTE relationships were significant at $110 \% \mathrm{PWC}_{\mathrm{FT}}$, but not at 90 or $100 \% \mathrm{PWC}_{\mathrm{FT}}$ (Figure 1). Thus, the constant velocity runs to exhaustion resulted in significant increases in muscle activation across time at $110 \%$ $\mathrm{PWC}_{\mathrm{FT}}$, but remained constant at 90 and $100 \%$ $\mathrm{PWC}_{\mathrm{FT}}$. These findings indicated that the $\mathrm{PWC}_{\mathrm{FT}}$ treadmill test serves as a valid tool for accurately estimating the fastest running velocity that can be maintained for an extended period of time (i.e. 40-60 minutes) without evidence of neuromuscular fatigue. From a practical standpoint, the $\mathrm{PWC}_{\mathrm{FT}}$ treadmill test can potentially be applied to athletic and clinical populations to identify fatiguing from non-fatiguing running (or walking) velocities, prescribe exercise training intensities based on $\% \mathrm{PWC}_{\mathrm{FT}}$, determine the effectiveness of training programs and nutritional supplements as ergogenic aids, and assess the level of physical fitness and factors related to neuromuscular function and fatigue in the elderly.

\section{References}

Beaver, W.L., Wasserman, K., \& Whipp, B.J. (1986). A new method for detecting anaerobic threshold by gas exchange. Journal of Applied Physiology, 60(6), 2020-2027.

Briscoe, M.J., Forgach, M.S., Trifan, E., \& Malek, M.H. (2014). Validating the $\mathrm{EMG}_{\mathrm{FT}}$ from a single incremental cycling test. International Journal of Sports Medicine, 35(7), 566-570.

Camic, C.L., Housh, T.J., Johnson, G.O., Hendrix, C.R., Zuniga, J.M, Mielke, M., et al. (2010a). An EMG frequencybased test for estimating the neuromuscular fatigue threshold during cycle ergometry. European Journal of Applied Physiology, 108(2), 337-345.

Camic, C.L., Housh, T.J., Zuniga, J.M., Hendrix, C.R., Mielke, M., Johnston, G.O., et al. (2010b). Effects of argininebased supplements on the physical working capacity at the fatigue threshold. Journal of Strength and Conditioning Research, 24(5), 1306-1312.

Camic, C.L., Kovacs, A.J., Enquist, E.A., VanDusseldorp, T.A., \& Hill, E.C. (2014). An electromyographic-based test for estimating neuromuscular fatigue during incremental treadmill running. Physiological Measurement, 35(12), 2401-2413.

deVries, H.A., Brodowicz, G.R., Robertson, L.D., Svoboda, M.D., Schendel, J.S., Tichy, A.M., et al. (1989). Estimating physical working capacity and training changes in the elderly at the fatigue threshold $\left(\mathrm{PWC}_{\mathrm{FT}}\right)$. Ergonomics, 32(8), 967-977. 
deVries, H.A., Housh, T.J., Johnson, G.O., Evans, S.A., Tharp, G.D., Housh, D.J., et al. (1990). Factors affecting the estimation of physical working capacity at the fatigue threshold. Ergonomics, 33(1), 25-33.

Emerson, N.S., Fukuda, D.H., Stout, J.R., Robinson, E.H., McCormack, W.P., Scanlon, T.C., et al. (2014). Physical working capacity at fatigue threshold $\left(\mathrm{PWC}_{\mathrm{FT}}\right)$ is associated with sarcopenia-related body composition and measures of functionality in older adults. Archives of Gerontology and Geriatrics, 59(2), 300-304.

Gaesser, G.A., \& Poole, D.C. (1996). The slow component of oxygen uptake kinetics in humans. Exercise and Sport Sciences Reviews, 24, 35-71.

Hermens, H.J., Freriks, B., Merletti, R., Stegeman, D., Blok J., Rau, G., et al. (1999). SENIAM European recommendations for surface electromyography: Results of the SENIAM project. Enschede, The Netherlands: Roessingh Research and Development.

Jenkins, N.D., Buckner, S.L., Baker, R.B., Bergstrom, H.C., Cochrane, K.C., Weir, J.P., et al. (2014). Effects of 6 weeks of aerobic exercise combined with conjugated linoleic acid on the physical working capacity at the fatigue threshold. Journal of Strength and Conditioning Research, 28(8), 2127-2135.

Jones, A.M., \& Doust, J.H. (1996). A 1\% treadmill grade most accurately reflects the energetic cost of outdoor running. Journal of Sports Sciences, 14(4), 321-327.

Poole, D.C., Ward, S.A., Gardner, G.W., \& Whipp, B.J. (1988). Metabolic and respiratory profile of the upper limit for prolonged exercise in man. Ergonomics, 31(9), 1265-1279.

Poole, D.C., Ward, S.A., \& Whipp, B.J. (1990). The effects of training of the metabolic and respiratory profile of highintensity cycle ergometer exercise. European Journal of Applied Physiology, 59(6), 421-429.

Ribeiro, J.P., Hughes, V., Fielding, R.A., Holden, W., Evans, W., \& Knuttgen, H.G. (1986). Metabolic and ventilatory responses to steady state exercise relative to lactate thresholds. European Journal of Applied Physiology, 55(2), 215-221.

Stout, J.R., Cramer, J.T., Zoeller, R.F., Torok, D., Costa, P., Hoffman, J.R., et al. (2007a). Effects of $\beta$-alanine supplementation on the onset of neuromuscular fatigue and ventilatory threshold in women. Amino Acids, 32(3), 381-386.

Stout, J.R., Fragala, M.S., Hoffman, J.R., Robinson, E.H., McCormack, W.P., Townsend, J.R., et al. (2015). C-terminal agrin fragment is inversely related to neuromuscular fatigue in older men. Muscle and Nerve, 51(1), 132-133.

Stout, J.R., Graves, S.B., Cramer, J.T., Goldstein, E.R., Costa, P.B., Smith, A.E., et al. (2007b). Effects of creatine supplementation on the onset of neuromuscular fatigue threshold and muscle strength in elderly men and women (64-86 years). Journal of Nutrition, Health, and Aging, 11(6), 459-464.

Zak, R.B., Camic, C.L., Hill, E.C., Monaghan, M.M., Kovacs, A.J., \& Wright, G.A. (2015). Acute effects of an argininebased supplement on neuromuscular, ventilatory, and metabolic fatigue thresholds. Applied Physiology, Nutrition, and Metabolism, 40(4), 379-385.

Submitted: April 25, 2017

Accepted: July 1, 2017

Published Online First: September 20, 2017

Correspondence to:

Clayton L. Camic, Ph.D.

Assistant Professor

Exercise and Sport Science

124 Wittich Hall

University of Wisconsin-La Crosse

La Crosse, Wisconsin, USA 54601

Phone: (608) 785-6524

E-mail: ccamic@uwlax.edu 